\title{
Washing and Extraction of Metals from Contaminated Soil Constituents: Implications for Contaminated Simulated Soil and Metallurgical Wastes with Different Reagents
}

\author{
Sanja S. Potgieter-Vermaak ${ }^{1}$, Leonard U. Mgbeahuruike ${ }^{1}$, Lizelle van Dyk² ${ }^{2}$ Judith Barrett ${ }^{1}$, \\ Herman J. Potgieter 1,2 \\ ${ }^{1}$ Chemistry and Environmental Science Division, School of Science and the Environment, Manchester Metropolitan University, \\ Manchester, UK \\ ${ }^{2}$ School of Chemical and Metallurgical Engineering, University of the Witwatersrand, Johannesburg, South Africa \\ Email: leonardmgbeahuruike@yahoo.com
}

How to cite this paper: Potgieter-Vermaak, S.S., Mgbeahuruike, L.U., van Dyk, L., Barrett, J. and Potgieter, H.J. (2019) Washing and Extraction of Metals from Contaminated Soil Constituents: Implications for Contaminated Simulated Soil and Metallurgical Wastes with Different Reagents. Journal of Environmental Protection, 10, 651-671.

https://doi.org/10.4236/jep.2019.105039

Received: January 30, 2019

Accepted: May 20, 2019

Published: May 23, 2019

\section{Copyright $\odot 2019$ by author(s) and} Scientific Research Publishing Inc. This work is licensed under the Creative Commons Attribution International License (CC BY 4.0).

http://creativecommons.org/licenses/by/4.0/

(c) (i) Open Access

\begin{abstract}
Leaching behaviour of heavy metals (HMs) from simulated soil (SS), prepared according to standard guidelines, as well as its constituents (quartz sand (QS), bentonite clay (BC), and peat moss (PM)) were investigated. The study focused on a batch process with the aim of comparing the leaching potentials and metals solubilisation of ethylene diamine tetraacetic acid (EDTA), ethylene diamine disuccinic acid (EDDS), acetylacetone (Hacac), citric acid (CA), and tartaric acid (TA) for sustainable metal extraction purposes after a maximum leaching time of $60 \mathrm{~min}$. The HMs concentrations with which the constituents were spiked with was such that reflected a contaminated site. The recovery potentials of both the SS and its constituents were found to vary for single metal (SM) and multi-metal (MM) systems. EDTA was the most efficient (on average $31 \%$ and $33 \%$ for SM and MM) and TA the least efficient (on average of $2 \%$ and $3 \%$ for SM and MM) extractant. For Hacac, preferential recovery for $\mathrm{Cu}$ and $\mathrm{Ni}$ were significant when compared to the other metals, while, metal recovery by EDDS in SS was lower than could be expected. The leaching trend for the targeted metals was studied using conventional leaching models.
\end{abstract}

\section{Keywords}

HMs, Leaching, Chelants, Pollution, Metallurgical Wastes, Contaminated Soil 


\section{Introduction}

Soil pollution is a global issue [1] [2] [3] and is usually the result of human activities, such as mining and metallurgical activities [4], oil refining [5], traffic [6], chemical plant processes [7] and agricultural production [8]. Whilst such pollution has often occurred before sufficient environmental legislation was introduced, much of these are continuing nowadays [9]. The danger of soil pollution is that selected pollutants can enter the human food chain with subsequent health consequences to the general population [10]. Moreover, run-off from such sites can potentially enter waterways with further consequences to water quality, security and endangering of aquatic ecosystems [11].

There are many reported incidences of soil quality being affected by different contaminants. Due to the diverse origin of these HMs, contaminated soils often contain a cocktail of inorganic compounds [5] [12]. Previous research suggests that $\mathrm{HMs}$ commonly found to contaminate soils include $\mathrm{Cd}, \mathrm{Cr}, \mathrm{Cu}, \mathrm{Ni}, \mathrm{Pb}$, and Zn [13] [14] [15]. While all contaminants come with their own set of consequences, dangers, and challenges to remediate, the focus in the current study will be primarily on five very common $\mathrm{HMs}$, i.e. $\mathrm{Cd}, \mathrm{Cu}, \mathrm{Ni}, \mathrm{Pb}$, and $\mathrm{Zn}$. The influence such HMs can jointly exert on remediative strategies to remove them from contaminated soils, either on their own or as a cocktail of metal ions, is being investigated in this paper.

There have been many studies reported on soil pollution and potential approaches to remediate it [14] [15]. A typical remediation approach is to wash the soil with a particular washing agent, often one that can form a complex with the contaminants, to remove it from the soil. Different types of washing agents employ different mechanisms to remove the HMs from contaminated soils, for example, by forming complexes with the metal ions in the case of EDTA and EDDS [16]. Other mechanisms include acid leaching with weak organic acids like citric acid, oxalic acid or tartaric acid [17] or through desorption through the action of water on contaminated soil. The effectiveness of any remedial treatment will depend, apart from other factors such as stirring, solid: liquid ratio and temperature, very much on the washing agent used, time, $\mathrm{pH}$ conditions and the interaction mechanism between the washing agent and the HM to be removed from the contaminated material.

Soil seldom consists of one single component and is usually a complex mixture of various components materials, such as sand [18], clay, organic matter, and silt [19] [20]. The different combination of such components is instrumental in giving individual soils their own unique metal binding properties. For example, clay is generally well known to adsorb and bind metal ions very successfully by replacing alkali and alkali earth metals [21]. This property is often described and quantified by the term "cation exchange capacity" or "cec". In the same manner organic matter, e.g. peat moss, contain humic and fulvic acids that can bind to metal cations and form complexes which limit the mobility of these metal cations [22] [23]. Often organic material in soil is porous in nature, which creates an additional avenue for the adsorption and capture of HM [24]. Quartz, 
the major constituent of sand, on the other hand, consists of solid particles with poor adsorption affinity for heavy metal cations [25]. The presence/absence, character, quantities, and arrangements of these constituents describe the ultimate soil properties and behaviour.

Common factors like $\mathrm{pH}$, temperature, and concentration all play a role in any chemical reaction/leaching or adsorption process. In extractive metallurgy, mineralogical and geo-metallurgical factors are of prime importance in metals recovery from any mined ore. It can, therefore, be expected that leaching and extraction of heavy metals from contaminated soils and wastes will be equally influenced by the soil composition and constituents. The macro influences of soil constituents, washing agents and presence of HMs (more specifically heavy metal cation(s)) are therefore likely to be dominating factors in the successful remediation of any polluted soil. This paper will describe an investigation into the interplay between these different components, washing/leaching reagents and the $\mathrm{HMs}, \mathrm{Cd}, \mathrm{Cu}, \mathrm{Ni}, \mathrm{Pb}$, and $\mathrm{Zn}$ to determine whether it could assist in selecting the optimum conditions for the remediation of natural soils and other polluted wastes. In addition, the profiles of the process of metal removal will be gauged to provide guidelines for choosing an appropriate unit process or combination of processes, which could be selected for such an operation. This could also provide the necessary basis for design purposes of treatment equipment, which can then be applied to other applications in this field, e.g. mining and metallurgical wastes or oil-polluted areas such as the Niger Delta.

The target concentrations of heavy metal contaminants used in this investigation were selected so that they were three times the intervention values set as regulatory limits by the Department of Petroleum Resources in Nigeria. The reason for using this particular level of concentration was to provide a realistic estimation for the rehabilitation of contaminated urban and rural land in Nigeria. The rationale behind the chosen concentrations was to simulate heavily contaminated soil typical of industrial waste dumps and oil contaminated land in the Niger Delta in Nigeria. This paper will describe and discuss the results obtained in the investigation.

\section{Materials and Methods}

\subsection{Chemicals and Materials}

Commercial samples of three individual substrates $(\mathrm{BC}=$ bentonite clay, $\mathrm{PM}=$ peat moss, QS = quartz sand; all sourced from local shops) as well as their composite substrate, simulated soil (SS), were selected for this study. This approach was based on other published reports of synthetic soil mixtures widely used as reference soil in the testing of complex solid samples [26] [27]. The PM was air dried to a constant weight, ground in a porcelain mortar and pestle, and sieved $(<1 \mathrm{~mm})$. The QS was washed with nitric acid to remove external contamination, allowed to air dry to constant mass and sieved to $<2 \mathrm{~mm}$. The BC was used as received. The SS was prepared according to the "recipe" described in the guidelines of the Organization for Economic Cooperation and Development 
(OECD) [28] [29]. The reference soil was composed of the following: Bentonite, $20 \%$; quartz sand, $70 \%$; peat moss, $10 \%$. OECD soil may not exactly mimic the behaviour of a natural soil; however, it was used as a simple model. The substrates were contaminated using atomic absorption standard solutions $\left(1000 \mathrm{mg} \cdot \mathrm{dm}^{-3}\right)$ purchased from Sigma Aldrich. Leaching agents: EDTA $\left(\mathrm{C}_{10} \mathrm{H}_{14} \mathrm{~N}_{2} \mathrm{O}_{8} \mathrm{Na}_{2} \cdot \mathrm{H}_{2} \mathrm{O}\right)$, Citric and Tartaric acid; EDDS $\left(\mathrm{C}_{10} \mathrm{H}_{16} \mathrm{~N}_{2} \mathrm{O}_{8}\right)$; Acetylacetone $\left(\mathrm{C}_{5} \mathrm{H}_{8} \mathrm{O}_{2}\right)$; were purchased from Sigma Aldrich, Innospec and Alfa Aeser, respectively. All mineral acids used in the analysis were of analytical or spectral grade.

\subsection{Experimental Methods}

The constituents were analysed for their physical and chemical properties, using standard techniques and approaches. Total organic carbon (TOC) was determined as the loss on ignition (LOI) as described by Goldin [30], using an electrical muffle furnace (Omegagalux-LMF3550). The $\mathrm{pH}$ was analysed in deionised water extracts (with a 1:10 solid to liquid ratio) using a digital $\mathrm{pH}$ meter (Mettler Toledo) [31]. Cation exchange capacity (CEC) and specific surface area (SSA) were determined as described by Cokca and Birand [32], and Santamarina et al. [33]. Particle size distribution was determined by using a laser particle size analyser (Malvern Masterizer 2000) and standard approaches. The mineralogy and morphology of samples were investigated using $\mathrm{x}$-ray diffraction (XRD-X'Pert) and scanning electron microscopy coupled with an energy dispersive $\mathrm{x}$-ray analyser (SEM-EDX Zeiss Supra 40VP). The baseline metal concentrations of the different substrates were determined after microwave-assisted digestion in concentrated nitric acid, using inductively coupled plasma optical emission spectroscopy (ICP-OES, iCap 6300 Thermo Scientific). All sample concentrations were corrected for matrix effects by procedural blanks, normalized to sample mass and reported as $\mathrm{mg} \cdot \mathrm{kg}^{-1}$ dry weight. Matrix-matched calibration (with blank) was performed using a multi-element standard solution (100 $\mathrm{mg} \cdot \mathrm{dm}^{-3}$ ) for each element. This yielded calibration graphs with correlation coefficients of $\geq 0.9995$ for each of the metals analysed. This analysis procedure was followed throughout the investigation to determine the target metal concentrations. The limits of detection (LOD) for the ICP-OES according to the analysed elements were $\mathrm{Cd}$ (0.0001), $\mathrm{Cu}$ (0.0022), $\mathrm{Ni}$ (0.0009), $\mathrm{Pb}(0.0008)$, and $\mathrm{Zn}(0.0027) \mathrm{mg} \cdot \mathrm{dm}^{-3}$.

\subsection{Experimental Methodology}

The air-dried individual soil constituents, as well as the composed SS, were accurately weighed to constant weight $(20 \mathrm{~g} \pm 0.0005 \mathrm{~g}$ for QS and BC, $5 \mathrm{~g} \pm 0.0002$ $\mathrm{g}$ for PM), transferred to a beaker and rewetted to a moisture content of $15 \%$ (by dry weight). The substrates were artificially contaminated using $200 \mathrm{~cm}^{3}$ of solutions (for QS and $\mathrm{BC}$, but $50 \mathrm{~cm}^{3}$ for PM) of the target metals at varying concentrations (substrates were contaminated with single metals as well as a multi-metal solution) to reach final concentrations as indicated in Table 1. Table 1 summarizes the data for single metal systems, the target concentration and the achieved loading for the different substrates. Substrates were found to have 
Table 1. Concentrations (mg. $\mathrm{kg}^{-1}$ ) of the five target metals loaded onto the different soil constituents.

\begin{tabular}{|c|c|c|c|c|c|}
\hline \multirow{3}{*}{ Metal } & \multicolumn{5}{|c|}{ Concentration $\left(\mathrm{mg} \cdot \mathrm{kg}^{-1}\right)$} \\
\hline & \multirow{2}{*}{ Target loading } & \multicolumn{4}{|c|}{ Achieved loading } \\
\hline & & $\mathrm{BC}$ & $\mathrm{PM}$ & QS & SS \\
\hline $\mathrm{Cd}$ & 50 & 48 & 49 & 6 & 48 \\
\hline $\mathrm{Cu}$ & 570 & 558 & 562 & 195 & 551 \\
\hline $\mathrm{Ni}$ & 630 & 571 & 570 & 13.9 & 589 \\
\hline $\mathrm{Pb}$ & 1590 & 1571 & 1579 & 148 & 1501 \\
\hline $\mathrm{Zn}$ & 2160 & 2153 & 2059 & 759 & 2148 \\
\hline
\end{tabular}

single metal loading efficiencies of $97 \% \pm 3.55 \%, 97 \% \pm 3.66 \%$, and $96 \% \pm 2.37 \%$ for the BC, PM, and SS respectively. However, the QS, as anticipated, showed low retention, due to its low CEC $(2.0 \mathrm{meq} / 100 \mathrm{~g})$, as such, its contribution to the overall capacity of adsorption was negligible. It was noted that the SS had loading efficiencies that were similar to that of $\mathrm{BC}$ and $\mathrm{PM}$, leading to the conclusion that the metals loading on the QS contributed little, if at all, to the overall HM soil loading. Achieved loadings for the multi-metals systems were, within experimental error, the same as that observed for the single-metal systems. The metals depicted in Table 1 were selected based on typical industrial soil contamination concentrations found in Nigeria, their potential to generate revenue when recovered to offset treatment costs, high toxicity, as well as their abundance in the environment.

The $\mathrm{pH}$ was measured following conventional protocols [31].

A batch-leaching process was used to study the recovery and removal of the metals loaded onto the different substrates. The leaching agents used were acetylacetone (2,4-pentanedione, referred to as Hacac hereafter), EDDS, citric acid (referred to as CA hereafter), tartaric acid (referred to as TA hereafter) and EDTA. Factors influencing the choice of leaching agents were: 1) cost, 2) environmental sustainability, 3) potential leaching efficiency, and 4) potential to be used in a different phase or modified for selective recovery. In particular, EDTA was included in the study as a regularly used standard treatment. To perform the batch process, $20 \mathrm{~g} \pm 0.0003 \mathrm{~g}$ of dried contaminated substrate $(5 \mathrm{~g} \pm 0.0002 \mathrm{~g}$ in the case of PM due to the volume that $20 \mathrm{~g}$ occupied) was placed in polypropylene tubes of $500 \mathrm{~cm}^{3}$ capacity containing $200 \mathrm{~cm}^{3}\left(50 \mathrm{~cm}^{3}\right.$ for PM) of leaching solution at a solid/liquid ratio of 1:10 (Hendershot and Tejowulan, 1998). A range of concentrations were used for the extractants, based on previous studies reported in literature [34] [35]. EDTA was employed at $0.034 \mathrm{mold} \cdot \mathrm{m}^{-3}$, EDDS at $0.034 \mathrm{mold} \cdot \mathrm{m}^{-3}, \mathrm{Hacac}$ at $0.03 \mathrm{mold} \cdot \mathrm{m}^{-3}, \mathrm{CA}$ at $0.026 \mathrm{mold} \cdot \mathrm{m}^{-3}$ and TA at $0.033 \mathrm{mold} \cdot \mathrm{m}^{-3}$. All these concentrations ensured an excess of extractant for each metal concerned. The change in $\mathrm{pH}$ upon exposure to the leaching agent was 
monitored by measuring the $\mathrm{pH}$ of the solution. The mixtures were centrifuged at $3000 \mathrm{rpm}$ after 5, 10,20, and $30 \mathrm{~min}$ of exposure to the metal-containing solutions. A procedural blank of deionized water as extractant was employed for all the different substrates. The $\mathrm{pH}$ of the supernatant was measured after $30 \mathrm{~min}$ of contact time to establish any possible changes. After each run, an aliquot of the supernatant $\left(1 \mathrm{~cm}^{3}\right)$ solution was filtrated with a syringe filter $(0.45 \mu \mathrm{m})$ into a plastic vial of $15 \mathrm{~cm}^{3}$ capacity and later made up to $10 \mathrm{~cm}^{3}$ with deionized water. Subsequently, the filtrates were analysed by ICP-OES and the selected metal concentrations retained in the adsorbent phase $\left(\mathrm{mg} \cdot \mathrm{kg}^{-1}\right)$ were calculated. The percentage of metal leached from the soil was calculated using Equation (1):

$$
\% \text { Metal leached }=\frac{\text { mass of metal in supernatant }}{\text { mass of metal originally loaded on substrate }}
$$

To ensure repeatability, this procedure was carried out in triplicate for all substrates.

\subsection{Kinetic Models}

The release of the different heavy metals is of importance to understand how fast contaminants can be transferred from the solid phase to the liquid phase for recovery purposes. For this study, the extraction profiles of $\mathrm{Cd}, \mathrm{Cu}, \mathrm{Ni}, \mathrm{Pb}$, and $\mathrm{Zn}$ from SS, BC, PM, and QS using the selected extractants EDTA, EDDS, ACAC, $\mathrm{CA}$, and TA were studied. While not being strictly speaking kinetic investigations, due to the limited data collected during the profile runs, several empirical kinetic equations, including the first order, Elovich, and power function equations to describe the leaching process were nevertheless fitted to the data to determine their potential predictive value for future further work. These kinetic functions were selected because of their common occurrence and application in literature to describe soil release reactions [32] [33] [36]. Moreover, the amount of metals released was plotted against time for each substrate and extractant used, and different kinetic equations were fitted to the extraction data. A brief description of each equation and the basis for its formulation is given below to provide more clarity on the differences between them.

\subsection{Power Function Model [36]}

The frictional power function model is a modified form of the Freundlich equation and its linear form is given in Equation (2):

$$
\ln q_{t}=\ln a+b \ln t
$$

where $q_{t}=$ the amount of metal $\left(\mathrm{mg} \cdot \mathrm{kg}^{-1}\right)$ leached or desorbed by the extracting agent after time $\mathrm{t}$, and $a$ and $b$ are empirical rate constants. The value of $a$ is directly proportional to the release rate of the metal at all values of $t$ and reflects the cumulative release of the metal at $t=1$, and the value of $b$ indicates how the release rate of the metal changes with time [37]. 


\subsection{Elovich Model}

The Elovich equation (Low, 1960) (Low, 1960) is generally expressed as reported below (Equation (3)):

$$
\frac{d_{q t}}{d t} a \exp (-\beta q t)
$$

If it is assumed that $a \beta t \gg 1$ then when applying the boundary conditions of $q_{t}=0$, at $t=0$ and $q_{t}=q t$, at $t=t$ (given by Chien and Clayton (Chien and Clayton, 1980)), the Elovich equation can be modified and simplified to Equation (4) (Havlin and Westfall, 1985):

$$
q_{t}=a+\frac{1}{\beta} \ln t
$$

Here $q_{t}=$ the amount of metal(s) $\left(\mathrm{mg} \cdot \mathrm{kg}^{-1}\right)$ desorbed/leached at a time $t$, and a and $1 / \beta$ are constants. If the leaching behaviour of the targeted metals by the extractant can be described by the Elovich model, a plot of $q_{t}$ versus $\ln t$ should yield a linear relationship with a slope of $1 / \beta$ and an intercept of $\exp ^{-\alpha \beta}$. Thus, the constants can be obtained from the slope and intercept of the straight line.

\subsection{First-Order Model}

The first-order equation (Equation (5)) as described by Martin and Spark (Martin and Sparks, 1983) is:

$$
\ln \left(q_{e}-q_{t}\right)=a-k_{1} t
$$

where $q_{t}$ and $q_{e}$ are the amounts desorbed (mg.kg ${ }^{-1}$ ) at time $\mathrm{t}$ and at equilibrium, respectively, and $k_{1}$ is the rate constant of the pseudo-first-order desorption/leaching process $\left(s^{-1}\right)$. A straight line plot of $\ln \left(q_{e}-q_{t}\right)$ against $t$ of the experimental data was used to determine the rate constant, $k_{1}$.

The goodness of fit of each model was evaluated according to its correlation coefficient $\left(R^{2}\right)$ and standard error of estimate (SE) calculated from Equation (6), where $q$ and $q$ are measured and predicted amounts of metals leached at time $t$, respectively, and $\mathrm{n}$ is the number of measurements.

$$
S E=\left[\frac{\sum\left(q_{\text {measured }}-q_{\text {predicted }}\right)^{2}}{(n-2)}\right] 0.5
$$

The significant difference of amount of $\mathrm{Cd}, \mathrm{Cu}, \mathrm{Ni}, \mathrm{Pb}$, and $\mathrm{Zn}$ desorption between the various substrates was determined by using a box plot (illustrated and discussed in the results).

\section{Results and Discussions}

\subsection{Substrate Characteristics}

Selected physicochemical properties of the SS and its components are summarized in Table 2. The composition of the SS (QS:BC:PM = 70:20:10) could be broadly classified as sandy soil, and similar to other such soils described in 
Table 2. Physicochemical properties of the simulated soil, as well as its constituents, compared with selected published data.

\begin{tabular}{|c|c|c|c|}
\hline \multicolumn{2}{|l|}{ Properties } & $\begin{array}{l}\text { Simulated soil } \\
\text { This Study }\end{array}$ & $\begin{array}{l}\text { References (soil name used in original } \\
\text { paper), soil taxonomic description }\end{array}$ \\
\hline & QS & pH: 4.15 & \\
\hline & $\mathrm{BC}$ & pH: 10.55 & \\
\hline & $\mathrm{PM}$ & pH: 4.97 & \\
\hline \multicolumn{2}{|c|}{${ }^{\mathrm{b}} \mathrm{CEC}(\mathrm{meq} / 100 \mathrm{~g})$} & $17 \pm 0.63$ & $\begin{array}{c}\text { 17.6 Sun et al. [45] } \\
\text { (Northern France, loam) }\end{array}$ \\
\hline \multicolumn{2}{|l|}{${ }^{\mathrm{c} S S A}\left(\mathrm{~m}^{2} / \mathrm{g}\right)$} & $31 \pm 1.38$ & $\begin{array}{l}55.8 \text { Kovo et al. }[42] \\
\text { (soil, clayey) }\end{array}$ \\
\hline \multicolumn{2}{|l|}{${ }^{\mathrm{d}}$ LOI (\%) } & 14 & $\begin{array}{l}\text { 13.6 Kovo et al. }[42] \\
\text { (soil, clayey) }\end{array}$ \\
\hline \multicolumn{2}{|c|}{ Mineralogy of SS } & $\begin{array}{c}\text { Montmorillonite } \\
\left(\mathrm{Na}_{0.2} \mathrm{Ca}_{0.1} \mathrm{Al}_{2} \mathrm{Si}_{4} \mathrm{O}_{10}(\mathrm{OH})_{2}\left(\mathrm{H}_{2} \mathrm{O}\right)_{10}\right. \\
\text { Quartz }\left(\mathrm{SiO}_{2}\right)\end{array}$ & $\begin{array}{l}\text { Montmorillonite, Quartz, Kaolinite. } \\
\text { Kovo et al. [42] (soil, clayey) }\end{array}$ \\
\hline \multirow{5}{*}{$\begin{array}{c}{ }^{\mathrm{e}} \text { Base-line } \\
\text { acid-soluble } \\
\text { metal } \\
\text { concentrations } \\
\text { in SS }\left(\mathrm{mg} \cdot \mathrm{kg}^{-1}\right)\end{array}$} & $\mathrm{Zn}$ & $55.4 \pm 2.38$ & $\begin{array}{l}\text { 49.4 Sun et al. [45] } \\
\text { (North France, loam) }\end{array}$ \\
\hline & $\mathrm{Cu}$ & $9.6 \pm 1.10$ & nd \\
\hline & $\mathrm{Ni}$ & $1.7 \pm 0.68$ & nd \\
\hline & $\mathrm{Cd}$ & $0.2 \pm 0.07$ & 0.2 Sun et al. [45] (North France, loam) \\
\hline & $\mathrm{Pb}$ & $12.4 \pm 0.13$ & nd \\
\hline
\end{tabular}

${ }^{\mathrm{a}} 1$ : 10 soil/deionized water ratio, ${ }^{\mathrm{b} C a t i o n}$ exchange capacity (meq/100g), 'Surface area $\left(\mathrm{m}^{2} / \mathrm{g}\right)$, ${ }^{\mathrm{d}}$ Loss on ignition (\%); ${ }^{e}$ Concentration determined after digestion with nitric acid $\left(\mathrm{mg}^{\mathrm{kg}} \mathrm{kg}^{-1}\right)$. Values shown are means \pm standard deviation, nd: not determined.

literature [38]. It was observed that the SS is had similar characteristics to that determined for another mined and treated soil [39]. The CEC (cation exchange capacity) of QS (the main component of the SS) is typically very low and in the range of $2 \mathrm{meq} / 100 \mathrm{~g}$. The CEC of the SS is in agreement with soil from France [40] and is in the expected range for such materials ( $15-20 \mathrm{meq} / 100 \mathrm{~g})$. It also reflects the clay content and its contribution to the properties of the SS, since clay and organic matter both have much larger CEC values than what we report here for the SS. The CEC value correlates well with the observed CEC reported by Peterson et al. [41] However, the specific surface area (SSA) of the SS was slightly lower than the value reported by other researchers [42]. This variation could be attributed to the soil forming, soil processes and soil morphology of natural soil [43] [44]. Secondary electron images (SEI), as shown in Figure 1, indicates the different QS, BC, PM, and SS morphologies.

The inherent content of the metals of interest as displayed in Table 2 are in the low $\mathrm{mg} \cdot \mathrm{kg}^{-1}$ range and typical of the composition expected from the pure constituents used to make up the SS. The Zn concentration in the SS fraction was significantly higher than the rest of the selected metals $\left(49.4 \mathrm{mg} \cdot \mathrm{kg}^{-1}\right)$, but similar than that reported in literature for natural soils [45].

The properties of the SS seem to be similar to some natural soils in Table 2, and therefore provide confidence that it can be used as a proxy to predict natural soil behaviour in the batch leaching process investigated and discussed in this paper. 


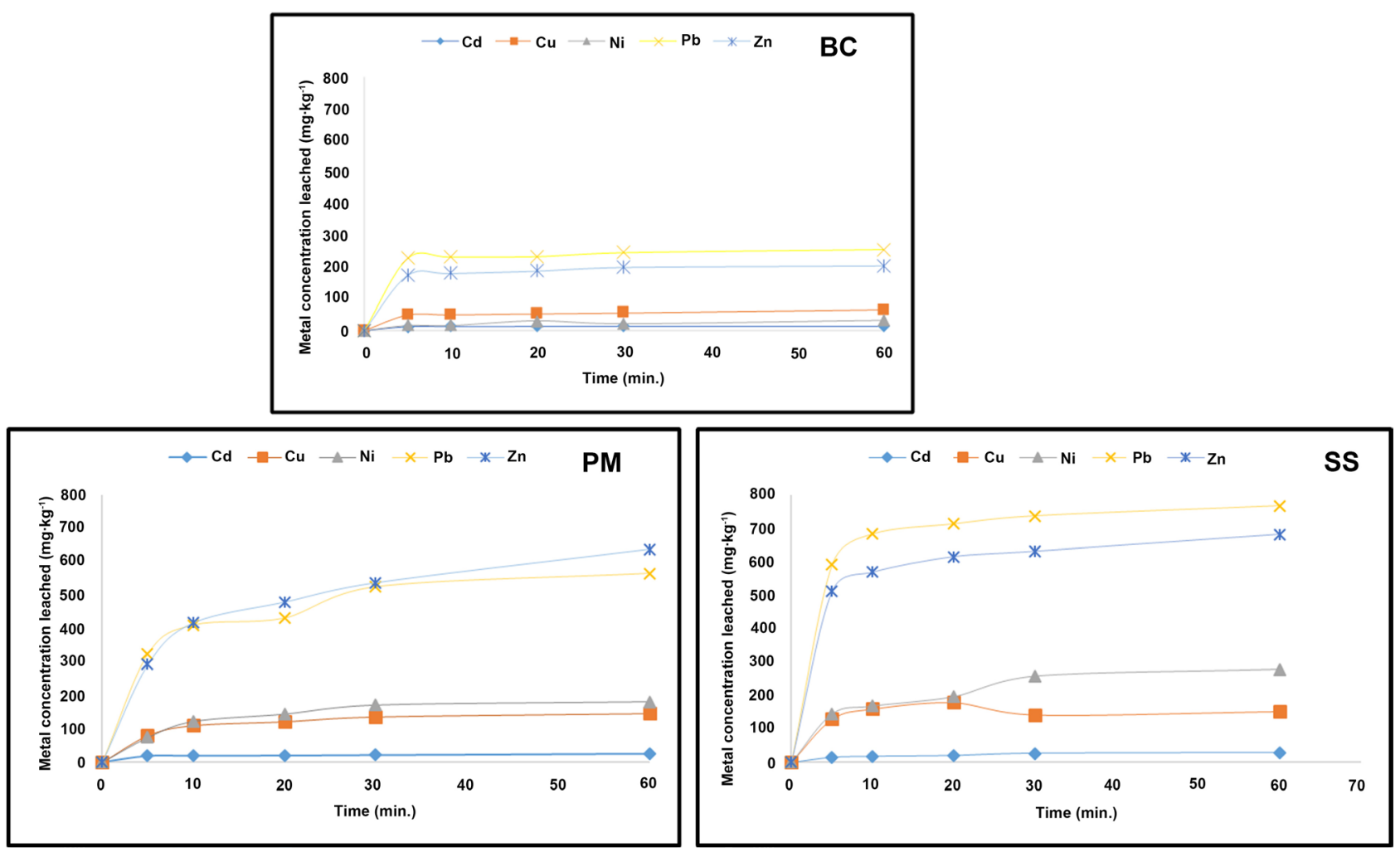

Figure 1. Leaching profile of single metal contaminated substrates (BC, PM, and SS) exposed to EDTA over time.

\section{2. $\mathrm{pH}$}

As the acidity/basicity of the soil and soil with extractant will play an important role in the mobilisation of the metal contaminants, the $\mathrm{pH}$ of the contaminated QS, BC, PM, and SS were measured before and after different extractants were added. The $\mathrm{pH}$ range of the extractants varied from 2.6 - 4.8 as would be expected in a reducing environment and therefore, they are all acidic. The low $\mathrm{pH}$ after addition of the extractants will evidently aid mobilisation of the metals and is expected to improve the extraction efficiency.

\subsection{Batch Extractions}

Using a batch approach and a 1:10 solid to liquid ratio, the leaching behaviour of the 5 metals of interest from the single soil components and the compiled SS was investigated. To illustrate the general leaching profile over time, the leaching concentrations $\left(\mathrm{mg} \cdot \mathrm{kg}^{-1}\right)$ of metals from single-metal-contaminated substrates after 5, 10, 20 and 30 minutes contact time with EDTA (Figure 1) have been chosen. It was observed that for $\mathrm{QS}$ and $\mathrm{BC}$ the maximum leaching is reached within 5 minutes. By contrast, for SS and PM, the maximum is reached after 10 minutes. This trend was followed irrespective of whether single (SM) or multi-metal (MM) contamination of the substrate(s) (only SM profiles are shown) was used. The different substrates did, however, show different trends with regards to their extracting efficiencies and sequence with EDTA. Bentonite Clay leached in a decreasing order of magnitude: $\mathrm{Pb}>\mathrm{Zn}>\mathrm{Cu}>\mathrm{Ni} \sim \mathrm{Cd}$; $\mathrm{PM}$ 
leached in the order of: $\mathrm{Pb} \sim \mathrm{Zn}>\mathrm{Ni} \sim \mathrm{Cu}>\mathrm{Cd}$; in QS the leaching order was: $\mathrm{Zn}>\mathrm{Cu}>\mathrm{Pb}>\mathrm{Ni} \sim \mathrm{Cd}$, and for SS the order of leaching was: $\mathrm{Pb}>\mathrm{Zn}>\mathrm{Ni} \sim \mathrm{Cu}>$ $\mathrm{Cd}$. It is therefore observed that $\mathrm{Cd}$ always leached the least (on average over the 4 substrates, $14 \pm 7 \mathrm{mg} \cdot \mathrm{kg}^{-1}$ from the initial loading of $\left.50 \mathrm{mg} \cdot \mathrm{kg}^{-1}\right)$. Apart from $\mathrm{QS}, \mathrm{Pb}$ seems to leach the most (412 $\pm 270 \mathrm{mg} \cdot \mathrm{kg}^{-1}$ from the initial loading of $\left.1590 \mathrm{mg} \cdot \mathrm{kg}^{-1}\right)$ in terms of absolute values normalised to sample mass, followed by $\mathrm{Zn}\left(505 \pm 210 \mathrm{mg} \cdot \mathrm{kg}^{-1}\right.$ from the initial loading of $\left.2160 \mathrm{mg} \cdot \mathrm{kg}^{-1}\right)$. Cu leached $123 \pm 21.8 \mathrm{mg} \cdot \mathrm{kg}^{-1}$ from the initial loading of $570 \mathrm{mg} \cdot \mathrm{kg}^{-1}$. These values are comparable to those reported by Moon et al. [46] for real soils, even though a higher EDTA concentration was used and the metals were all present together. Moon et al. [46] extracted $\mathrm{Pb}, \mathrm{Cu}$, and $\mathrm{Zn}$ from a naturally polluted soil (characterised with a higher QS content (86\%), a slightly acidic $\mathrm{pH}$ and lower CEC) by washing it with $0.1 \mathrm{mold} \cdot \mathrm{m}^{-3}$ EDTA using a batch-type process. These authors [46] reported extractions of $\sim 450 \mathrm{mg} \cdot \mathrm{kg}^{-1}$ of $\mathrm{Pb}, \sim 200 \mathrm{mg} \cdot \mathrm{kg}^{-1}$ of $\mathrm{Cu}$ and $\sim 220 \mathrm{mg} \cdot \mathrm{kg}^{-1}$ of $\mathrm{Zn}$ after one-hour exposure.

From comparing the values over the range of substrates, it is clear that metals were retained on the soil components in the order: $\mathrm{BC}>\mathrm{PM}>\mathrm{SS}>\mathrm{QS}$. This appears to be in contrast to the CEC for the substrates, which are PM (130 meq $/ 100 \mathrm{~g})>$ BC $(92 \mathrm{meq} / 100 \mathrm{~g})>\mathrm{SS}(17 \mathrm{meq} / 100 \mathrm{~g})>\mathrm{QS}(0.9 \mathrm{meq} / 100 \mathrm{~g})$. This suggests that other capacity controlling properties, such as $\mathrm{pH}$, mass transfer limitations and saturation might have an influence on the retention behaviour. As the level of metal contamination is different for all metals, the discussion in the next section will focus on percentage recovery rather than normalised concentrations. To investigate the relationship between substrate, single/multi-metal contamination and leaching/washing agent, the substrates will be discussed individually below, except for QS. As mentioned previously, the loading efficiency and contribution of QS in the retention of the metals of interest were low and will therefore not be included in further discussions in this paper.

\subsubsection{Extraction Efficiency of Metals from Contaminated BC}

The BC contaminated with single metals as well as multi-metals (at three times their respective intervention values) were exposed to five extractants in a batch leaching process. The data is reported in Table 3.

For the SM-contaminated BC the average efficiency over all metals and extractants were $\sim 9 \%$ and ranged from $1 \%-24 \%$. If this is compared to the average extraction efficiency from QS at $92 \% \pm 5.6 \%$ (data not shown here) it is evident that the $\mathrm{BC}$ substrate more strongly retained all metals and therefore values for efficiencies are significantly lower than for QS. For the MM-contaminated $\mathrm{BC}$, the average was $11 \%$ and ranged from $1 \%-30 \%$ in comparison to an average of $82 \% \pm 9.8 \%$ for the QS (data not shown here). Taking the relatively large CEC value of $\mathrm{BC}$ into account, the retention of metals is not surprising. Furthermore, since BC is expandable clay (interlayer spacing $9.6 \AA$ - $16 \AA$ ) its interlayer spaces can be penetrated by exchangeable cations of similar or smaller 
Table 3. Comparison of the extraction efficiency of single and multi-metal contaminated Bentonite Clay using selected extractants (EDTA, EDDS, Hacac, CA, and TA at a total contact time of 5 minutes). The standard deviation on the values reported are in the range $\pm(0.01-0.08)(\mathrm{n}=3)$.

\begin{tabular}{ccccccccccc}
\hline \multirow{2}{*}{ Metals } & \multicolumn{8}{c}{ Extraction efficiency (\%) Single-metal leach } & \multicolumn{7}{c}{ Extraction efficiency (\%) } \\
\cline { 2 - 9 } & EDTA & EDDS & Hacac & CA & TA & EDTA & EDDS & Hacac leach & CA & TA \\
\hline $\mathrm{Cd}$ & 24 & 20 & 1 & 9 & 2 & 18 & 26 & 7 & 11 & 4 \\
$\mathrm{Cu}$ & 12 & 11 & 23 & 5 & 3 & 10 & 18 & 10 & 10 & 1 \\
$\mathrm{Ni}$ & 5 & 3 & 5 & 3 & 1 & 9 & 14 & 17 & 9 & 2 \\
$\mathrm{~Pb}$ & 16 & 20 & 2 & 12 & 3 & 19 & 30 & 3 & 10 & 3 \\
$\mathrm{Zn}$ & 9 & 12 & 10 & 9 & 3 & 10 & 18 & 14 & 8 & 2 \\
\hline
\end{tabular}

diameter as the interlayer spacing. Lead has a six-coordinate diameter of $1.33 \AA$, Cd $1.09 \AA$, Zn $0.88 \AA$, Cu $0.87 \AA$ and Ni $0.83 \AA$ A. All these metals could, therefore, have penetrated the interlayer spacing, since they are all smaller than the interlayer spacing. On average, the extraction efficiencies for the extractants were in the order: $\mathrm{EDTA} \approx \mathrm{EDDS}>\mathrm{Hacac} \approx \mathrm{CA}>\mathrm{TA}$ for the SM-contaminated BC. For the MM system it followed the order: EDDS $>$ EDTA $>$ Hacac $\approx \mathrm{CA}>\mathrm{TA}$. Although there is a small difference in the average percentage extraction, the MMand SM- systems behaved similarly. This is illustrated by the box plots in Figure 2. The graphical representation shows that the variations in both systems are similar and the extraction within experimental error the same for all metals and extractants. A synergistic effect is observed for $\mathrm{Ni}>\mathrm{Zn} \sim \mathrm{Cd}$, for which efficiency improves by between two- and three-fold. Even though this is the case, the differences are small.

\subsubsection{Extraction Efficiency of Metals from Contaminated PM}

Similar to QS and BC (Section 3.3.1), PM contaminated with single metals as well as multi-metals (at three times their respective intervention values) were exposed to five extractants in a batch process. The data is displayed in Table 4.

The data in Table 4 displayed extractions ranging from $1 \%-44 \%$ for SM contaminated PM and from 1\% - 45\% for MM-contaminated PM. On average, the extraction efficiencies for the extractants were in the order: EDTA > EDDS > Hacac > CA > TA for both $\mathrm{SM}$ and MM-contaminated PM. For the SM-contaminated PM the average efficiency over all metals and extractants were close to double that for BC at $14 \% \pm 13 \%$, and 1.5 times for the MM-contaminated $\mathrm{PM}$ at $16 \% \pm 14 \%$. EDTA significantly outperformed the other extractants, on average $31 \%$ of the metals for the SM-contaminated PM and $33 \%$ for the MM-contaminated PM were extracted, compared to $19 \%, 12 \%, 7 \%$ and $2 \%$ for SM; and 19\%, 14\%, 11\% and 3\% for MM with EDDS, Hacac, CA and TA, respectively. The high leaching potential of EDTA over other extractants can likely be attributed to its strong chelating ability for different heavy metals [39] [47] [48]. 


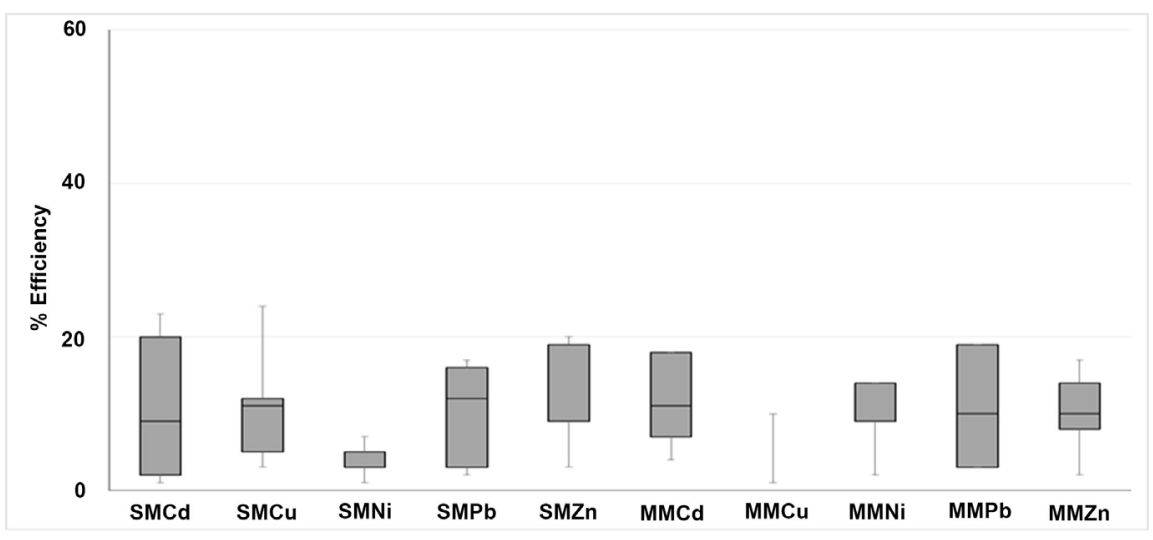

Figure 2. Illustration of the variance, $25 \%$ and $75 \%$ quartiles of the percentage metal leached from SM- and MM contaminated BC using the five extractants.

Table 4. Comparison of the extraction efficiency of single and multi-metal contaminated PM using selected extractants (EDTA, EDDS, ACAC, CA, and TA at a total contact time of 5 minutes). The standard deviation on the values reported are in the range $\pm(0.01-$ $0.08)(\mathrm{n}=3)$.

\begin{tabular}{ccccccccccc}
\hline \multirow{2}{*}{ Metals } & \multicolumn{3}{l}{ Extraction efficiency (\%) Single-metal leach } & \multicolumn{3}{c}{ Extraction efficiency (\%) Multi-metal leach } \\
\cline { 2 - 10 } & EDTA & EDDS & Hacac & CA & TA & EDTA & EDDS & Hacac & CA & TA \\
\hline $\mathrm{Cd}$ & 44 & 10 & 2 & 1 & 2 & 45 & 4 & 4 & 2 & 2 \\
$\mathrm{Cu}$ & 24 & 20 & 27 & 3 & 1 & 20 & 19 & 29 & 3 & 1 \\
$\mathrm{Ni}$ & 30 & 28 & 23 & 17 & 5 & 35 & 35 & 29 & 29 & 7 \\
$\mathrm{~Pb}$ & 33 & 10 & 2 & 1 & 1 & 33 & 10 & 1 & 1 & 1 \\
$\mathrm{Zn}$ & 26 & 29 & 8 & 14 & 3 & 30 & 25 & 9 & 18 & 6 \\
\hline
\end{tabular}

Although there is only a small difference in the average percentage extraction for the MM- and SM systems, there is a clear difference in behaviour, as illustrated by the box plots in Figure 3, which further highlights the dissimilarities and similarities in both systems.

Cadmium showed a lower degree of variance in the MM system than the SM system. This was also the case for $\mathrm{Ni}$, but to a lesser extent than for Cd. Similarly, variations in both SM- and MM contaminated PM were observed for the other metals. Synergistic effects were discerned for $\mathrm{Ni}$, for which enhanced extraction in the presence of the other metals across all extractants were observed. The other metals did not show any substantial difference.

\subsubsection{Extraction Efficiency of Metals from Contaminated SS}

Similarly to QS, BC (Section 3.3.1) and PM (Section 3.3.2), SS contaminated with SM as well as MM (at three times their respective intervention values) were exposed to five extractants in a batch process. The determined extraction efficiencies are summarized in Table 5.

As illustrated by Figure 4, the SM-contaminated SS had an average extraction efficiency of $21 \% \pm 15 \%$, while the MM-contaminated SS were $23 \% \pm 18 \%$. This 


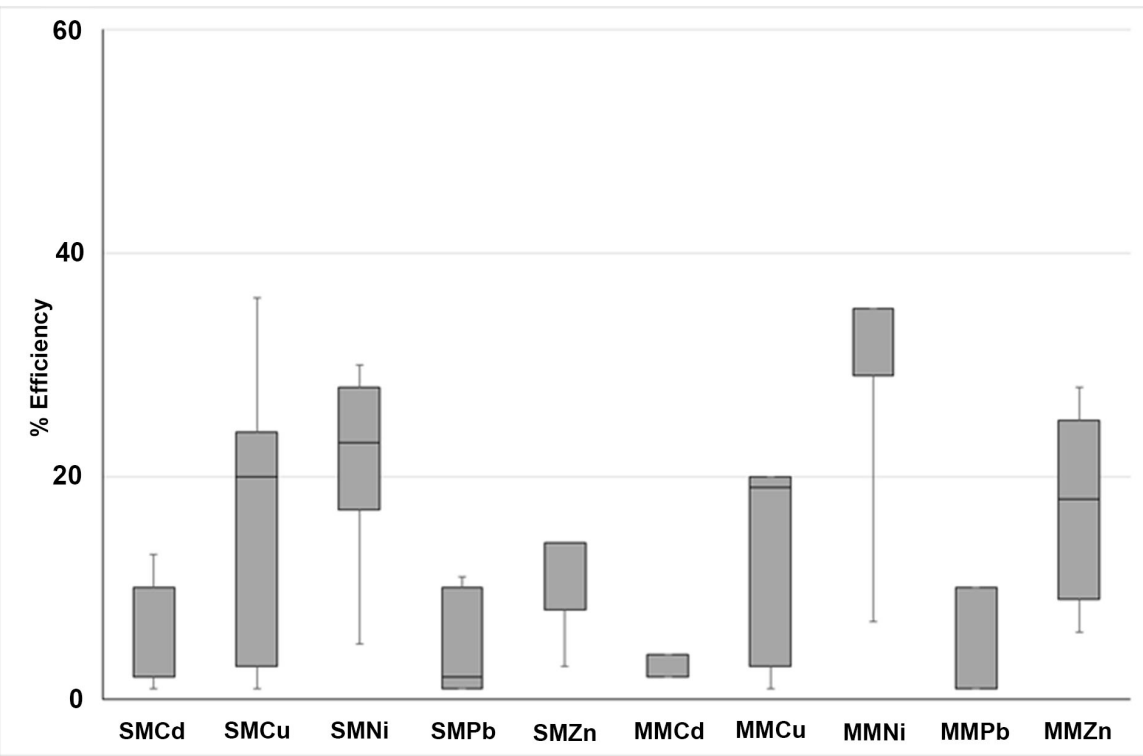

Figure 3. Box plot to illustrate the variance, $25 \%$ and $75 \%$ quartiles of the percentage metal leached from SM and MM contaminated PM using the 5 extractants.

Table 5. Comparison of the extraction efficiency of SM and MM contaminated SS using selected extractants (EDTA, EDDS, Hacac, CA, and TA at a total contact time of 5 minutes). The standard deviation on the values reported are in the range $\pm(0.01-0.08)(\mathrm{n}=$ 3).

\begin{tabular}{ccccccccccc}
\hline \multirow{2}{*}{ Metals } & \multicolumn{3}{c}{ Extraction efficiency (\%) Single-metal leach } & \multicolumn{3}{c}{ Extraction efficiency (\%) Multi-metal leach } \\
\cline { 2 - 9 } & EDTA & EDDS & Hacac & CA & TA & EDTA & EDDS & Hacac & CA & TA \\
\hline $\mathrm{Cd}$ & 42 & 28 & 2 & 11 & 9 & 60 & 8 & 8 & 16 & 17 \\
$\mathrm{Cu}$ & 33 & 10 & 46 & 19 & 10 & 32 & 6 & 28 & 23 & 6 \\
$\mathrm{Ni}$ & 33 & 14 & 51 & 30 & 16 & 49 & 5 & 51 & 50 & 29 \\
$\mathrm{~Pb}$ & 49 & 9 & 3 & 15 & 7 & 53 & 2 & 7 & 16 & 10 \\
$\mathrm{Zn}$ & 29 & 6 & 31 & 17 & 14 & 31 & 4 & 17 & 19 & 17 \\
\hline
\end{tabular}

suggests that the two systems had similar efficiencies overall. Calculating the expected percentage extraction using the ratio of QS:PM:BC $=70: 20: 10$ and using the results obtained for the single components, a much lower overall percentage extraction is obtained for both SM and MM systems than the calculated mass balance would suggest. For the SM-contaminated SS it was 3.2 times lower and for the MM, it was 2.7 times lower. This phenomenon suggests that the QS is not driving the process even though it is present as the largest fraction. The amount and rate of extraction clearly depended, amongst other things, on the presence and extraction behaviours of $\mathrm{BC}$ and PM.

For the SS, the extraction efficiency was in the order EDTA $>$ Hacac $>\mathrm{CA}>$ EDDS $>$ TA for SM and EDTA $>$ CA $>$ Hacac $>$ EDDS $>$ TA for MM. EDTA, in general, outperformed the other extractants by between 9 and 1.3 times, showing close similarity to the extraction efficiencies observed for PM. This may be 


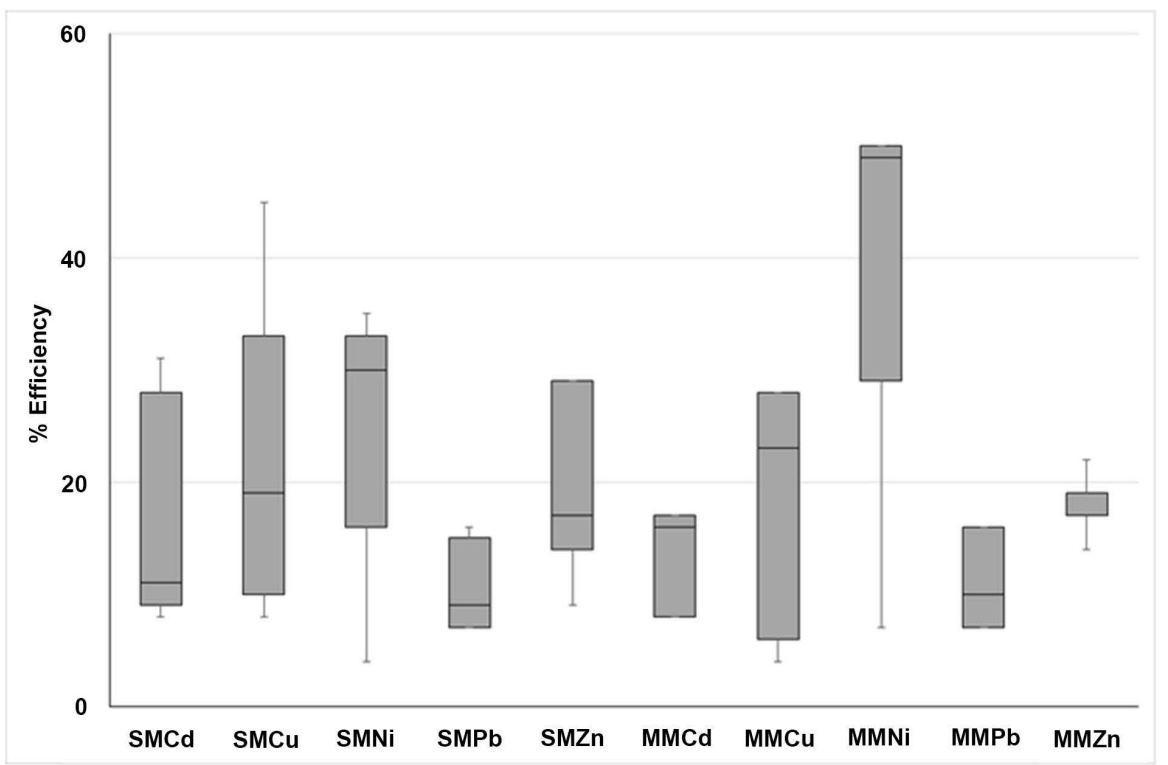

Figure 4. Box plots to illustrate the variance, $25 \%$ and $75 \%$ quartiles of the percentage metal leached from single- and multi-metal contaminated SS using the five extractants.

ascribed to the high stability constants $(\operatorname{logK} 16.5$ - 18.8) for EDTA with the respective metals. For EDTA the order of extraction followed the sequence: $\mathrm{Pb}$ $(49 \%)>\mathrm{Cd}(43 \%)>\mathrm{Ni}=\mathrm{Cu}(33 \%)>\mathrm{Zn}(29 \%)$ for the SM-contaminated SS and for the MM-contaminated SS Cd exhibited a higher efficiency than $\mathrm{Pb}$. Two thirds of the metals showed an increase in extraction efficiency for the MM-contaminated SS. EDDS displayed a similar order (Cd (28\%) > Ni (14\%) > $\mathrm{Cu}=\mathrm{Pb}(10 \%)>\mathrm{Zn}(6 \%))$ for the single metal-contaminated SS, all of which were significantly less mobile in the EDDS in comparison with the EDTA. The MM system showed very low efficiencies across the board. This may in part be explained by the stability constants for these metals being $10 \%-30 \%$ lower for EDDS than EDTA. The Hacac favoured the $\mathrm{Cu}$ and $\mathrm{Ni}$ ( $46 \%$ and $51 \%$, respectively) and showed much lower efficiencies for $\mathrm{Cd}, \mathrm{Zn}$, and $\mathrm{Pb}$. The extraction of $\mathrm{Ni}$ with Hacac also outperformed extraction with EDTA. This observation was to be expected as the stability constants for the acetylacetone complexes also follow this order [49]. The CA followed the order $\mathrm{Ni}(30 \%)>\mathrm{Cu}(19 \%)>\mathrm{Pb}$ $(17 \%)>\mathrm{Zn}(15 \%)>\mathrm{Cd}(11 \%)$ for the SM system and a similar order for the MM system. There seems to be a synergistic effect for all metals with this extractant used on the MM-contaminated SS and Ni was significantly favoured with a 50\% efficiency, which also outperformed EDTA. TA was again the poorest performer of all the extractants with a maximum extraction of $29 \%$ for $\mathrm{Ni}$ followed by $\mathrm{Cu}$, $\mathrm{Zn}, \mathrm{Pb}$, and $\mathrm{Cd}$. These results suggest that sequential extraction of the different metals could be achieved by exploiting the differences in efficiencies of the different washing/leaching agents on the different metals.

To compare the efficiencies of the leaching agents across the substrates, the order of the efficiencies for SS, PM, and BC are shown in Table 6. From the data one may be able to predict extraction efficiencies for natural or polluted soils 
Table 6. Comparison of the performance efficiency of selected extractants used for metal removal/recovery across the different substrates under investigation.

\begin{tabular}{clcc}
\hline Metal & SS & PM & BC \\
\hline Cd & EDTA $>$ EDDS $>$ CA $>$ TA $>$ Hacac & EDTA $>$ EDDS $>$ CA $>$ Hacac $>$ TA & EDTA $>$ EDDS $>$ CA $>$ Hacac $>$ TA \\
$\mathbf{C u}$ & EDTA $\approx$ Hacac $>$ CA $>$ EDDS $\approx$ TA & Hacac $>$ EDTA $>$ EDDS $>$ CA $>$ TA & EDTA $\approx$ EDDS $\approx$ Hacac $>$ CA $>$ TA \\
$\mathbf{N i}$ & Hacac $>$ EDTA $>$ CA $>$ TA $>$ EDDS & EDTA $\approx$ EDDS $\approx$ Hacac $>$ CA $>$ TA & EDTA $\approx$ Hacac $>$ EDDS $>$ CA $>$ TA \\
Pb & EDTA $>$ CA $>$ EDDS $>$ TA $>$ Hacac & EDTA $>$ EDDS $>$ CA $\approx$ TA $\approx$ Hacac & EDDS $>$ EDTA $>$ CA $>$ Hacac $\approx$ TA \\
Zn & EDTA $>$ Hacac $>$ CA $>$ TA $>$ EDDS & EDTA $\approx$ EDDS $>$ CA $>$ Hacac $>$ TA & EDDS $>$ EDTA $\approx$ Hacac $>$ CA $>$ TA \\
\hline
\end{tabular}

with a similar composition. It may also be possible to suggest potential sequential extractions. For example, it seems that Hacac favoured $\mathrm{Cu}$ and $\mathrm{Ni}$ and it may be possible to extract these two metals prior or after an EDTA extraction, resulting in higher overall removal percentages.

\subsection{Leaching/Extraction Profiles}

Three mathematical equations, the first order, Elovich, and power function equations, were fitted to the leaching profiles of $\mathrm{Cd}, \mathrm{Cu}, \mathrm{Ni}, \mathrm{Pb}$, and $\mathrm{Zn}$ for $\mathrm{SS}$, as well as the single component substrates. These functions were selected because of their common use in the literature. To determine the equation(s) that best described the leaching process, a standard error of estimate (SE) was calculated for each equation to determine their spread or variability with experimental data. A relatively high value of the correlation coefficient $\left(R^{2}\right)$ and low SE were used as criteria for the best fit [50]. The experimental profile data was fitted to the various kinetic equations discussed above to obtain the respective rate constants $a, b, k_{1}$, and $1 / \beta$. The first order and simple Elovich equations yielded low values of $R^{2}$ and high SE estimates and as such, are not discussed further (The values of interest for these two models can be found in the supplementary material). On the contrary, the power function equation appeared to give a better description of the leaching behaviour of the various metals as inferred from its $\mathrm{R}^{2}$ and SE values and the relevant data are given in Table 7. According to Motaghian [51] and references therein, this implies that the rate-determining step for this system is diffusion controlled.

In this study, "a" ranged from 0.01 to 5.73 with a mean value of 3.41 , and "b" from 0.04 to 0.46 with a mean of 0.18 . The calculated value of $(a \times b)$, ranged from 0.15 to 0.83 with a mean value of 0.53 (Table 7). Similar values for "b" have been reported in the study by Motaghian [51] and references therein, where they reported on DTPA extraction of $\mathrm{Cu}$ from calcareous soils. However, Motaghian reported a lower range for "a" of $(0.42-2.30)$, where the values for $\mathrm{Cu}$ extracted with EDTA from SS, PM, and BC in our study ranged from 2.83 - 3.82. This points to a faster release rate and may be a reflection of the different properties of the substrates between the two studies. Furthermore, following the reasoning of Motaghian [51] it can be concluded that the rate of release of all the metals decrease exponentially as "b" $<1$ across all substrates and extractants. As 
Table 7. Leaching profile parameters for $\mathrm{Cd}, \mathrm{Cu}, \mathrm{Ni}, \mathrm{Pb}$, and $\mathrm{Zn}$ leached from $\mathrm{SS}, \mathrm{BC}$, and $\mathrm{PM}$ using selected chelating agents (EDTA, EDDS, ACAC, CA, and TA) according to a power function model.

\begin{tabular}{|c|c|c|c|c|c|c|c|c|c|c|c|c|c|c|c|}
\hline & \multicolumn{3}{|c|}{ EDTA } & \multicolumn{3}{|c|}{ EDDS } & \multicolumn{3}{|c|}{ Hacac } & \multicolumn{3}{|c|}{$\mathrm{CA}$} & \multicolumn{3}{|c|}{ TA } \\
\hline & SS & $\mathrm{BC}$ & $\mathrm{PM}$ & SS & $\mathrm{BC}$ & $\mathrm{PM}$ & SS & $\mathrm{BC}$ & $\mathrm{PM}$ & SS & $\mathrm{BC}$ & $\mathrm{PM}$ & SS & $\mathrm{BC}$ & PM \\
\hline \multicolumn{16}{|c|}{$\mathrm{Cd}$} \\
\hline $\mathbf{a}$ & 1.52 & 2.91 & 2.54 & 1.03 & 1.73 & 1.3 & 0.38 & 0.14 & 1.3 & 1.96 & 1.16 & 0.49 & 1.14 & 0.89 & 0.37 \\
\hline$b$ & 0.21 & 0.05 & 0.07 & 0.21 & 0.08 & 0.18 & 0.18 & 0.09 & 0.18 & 0.48 & 0.05 & 0.14 & 0.04 & 0.18 & 0.09 \\
\hline$a^{*} b$ & 0.32 & 0.15 & 0.18 & 0.22 & 0.14 & 0.23 & 0.07 & 0.01 & 0.23 & 0.94 & 0.06 & 0.07 & 0.05 & 0.16 & 0.06 \\
\hline $\mathrm{R}^{2}$ & 0.99 & 0.99 & 0.99 & 0.99 & 0.99 & 0.90 & 0.9 & 0.9 & 0.9 & 0.99 & 0.99 & 0.90 & 0.99 & 0.99 & 0.90 \\
\hline SSE & 0.94 & 0.94 & 0.93 & 0.94 & 0.94 & 0.93 & 0.94 & 0.94 & 0.93 & 0.94 & 0.94 & 0.93 & 0.94 & 0.94 & 0.93 \\
\hline \multicolumn{16}{|c|}{$\mathrm{Cu}$} \\
\hline$b$ & 0.2 & 0.17 & 0.28 & 0.35 & 0.17 & 0.3 & 0.14 & 0.21 & 0.45 & 0.91 & 0.09 & 0.17 & 0.06 & 0.23 & 0.07 \\
\hline$a^{*} b$ & 0.76 & 0.49 & 0.79 & 0.47 & 0.49 & 0.74 & 0.57 & 0.51 & 0.77 & 0.61 & 0.23 & 0.24 & 0.21 & 0.33 & 0.09 \\
\hline $\mathbf{R}^{2}$ & 0.99 & 0.91 & 0.94 & 0.99 & 0.91 & 0.94 & 0.99 & 0.91 & 0.94 & 0.99 & 0.91 & 0.94 & 0.99 & 0.91 & 0.94 \\
\hline SSE & 1.64 & 1.21 & 1.44 & 1.64 & 1.21 & 1.44 & 1.64 & 1.21 & 1.44 & 1.64 & 1.21 & 1.44 & 1.64 & 1.21 & 1.44 \\
\hline \multicolumn{16}{|c|}{$\mathrm{Ni}$} \\
\hline a & 3.31 & 0.01 & 3.32 & 3.31 & 0.1 & 3.32 & 3.62 & 0.8 & 0.84 & 3.31 & 0.1 & 3.32 & 3.03 & 0.36 & 2.72 \\
\hline b & 0.25 & 0.46 & 0.17 & 0.25 & 0.35 & 0.17 & 0.29 & 0.33 & 0.56 & 0.25 & 0.35 & 0.17 & 0.2 & 0.2 & 0.08 \\
\hline$a^{\star} b$ & 0.83 & 0 & 0.56 & 0.83 & 0.04 & 0.56 & 1.05 & 0.26 & 0.47 & 0.83 & 0.04 & 0.56 & 0.61 & 0.07 & 0.22 \\
\hline $\mathbf{R}^{2}$ & 0.99 & 0.84 & 0.91 & 0.99 & 0.84 & 0.91 & 0.99 & 0.84 & 0.91 & 0.99 & 0.84 & 0.91 & 0.99 & 0.84 & 0.91 \\
\hline \multicolumn{16}{|c|}{$\mathrm{Pb}$} \\
\hline a & 5.73 & 5.12 & 4.42 & 3.35 & 5.12 & 3.26 & 2.74 & 0.4 & 3.26 & 3.38 & 4.93 & 1.74 & 4.51 & 3 & 4.42 \\
\hline b & 0.12 & 0.08 & 0.04 & 0.21 & 0.08 & 0.25 & 0.12 & 0.38 & 0.25 & 0.27 & 0.05 & 0.16 & 0.02 & 0.1 & 0.04 \\
\hline$a^{\star} b$ & 0.69 & 0.41 & 0.18 & 0.7 & 0.41 & 0.82 & 0.33 & 0.15 & 0.82 & 0.91 & 0.25 & 0.28 & 0.09 & 0.3 & 0.18 \\
\hline $\mathbf{R}^{2}$ & 0.92 & 0.87 & 0.93 & 0.97 & 0.87 & 0.93 & 0.83 & 0.87 & 0.93 & 0.95 & 0.87 & 0.93 & 0.87 & 0.87 & 0.93 \\
\hline SSE & 2.22 & 0.99 & 1.94 & 2.22 & 0.99 & 1.94 & 2.22 & 0.99 & 1.94 & 2.22 & 0.99 & 1.94 & 2.22 & 0.99 & 1.94 \\
\hline \multicolumn{16}{|c|}{$\mathrm{Zn}$} \\
\hline a & 5.57 & 3.24 & 3.86 & 5.17 & 3.24 & 5.05 & 3.32 & 4.04 & 1.02 & 5.17 & 5.69 & 3.76 & 4.56 & 3.24 & 3.1 \\
\hline b & 0.12 & 0.15 & 0.33 & 0.07 & 0.15 & 0.18 & 0.38 & 0.17 & 0.56 & 0.07 & 0.08 & 0.26 & 0.16 & 0.15 & 0.18 \\
\hline$a^{*} b$ & 0.67 & 0.49 & 1.27 & 0.36 & 0.49 & 0.91 & 1.26 & 0.69 & 0.57 & 0.36 & 0.46 & 0.98 & 0.73 & 0.49 & 0.56 \\
\hline $\mathbf{R}^{2}$ & 0.98 & 0.99 & 0.96 & 0.98 & 0.99 & 0.96 & 0.98 & 0.99 & 0.96 & 0.98 & 0.99 & 0.96 & 0.98 & 0.99 & 0.96 \\
\hline SSE & 2.16 & 1.81 & 1.88 & 2.16 & 1.81 & 1.88 & 2.16 & 1.88 & 1.88 & 2.16 & 1.81 & 1.88 & 2.16 & 1.81 & 1.88 \\
\hline
\end{tabular}

the equation of the power function indicates, there was a direct correlation between the product of "a" and " $b$ " and mass of metal leached (expressed as percentage leached), with correlation coefficients of $0.977,0.907,0.811,0.806$ and 0.703 for $\mathrm{Cd}, \mathrm{Ni}, \mathrm{Cu}, \mathrm{Pb}$, and $\mathrm{Zn}$ respectively. 

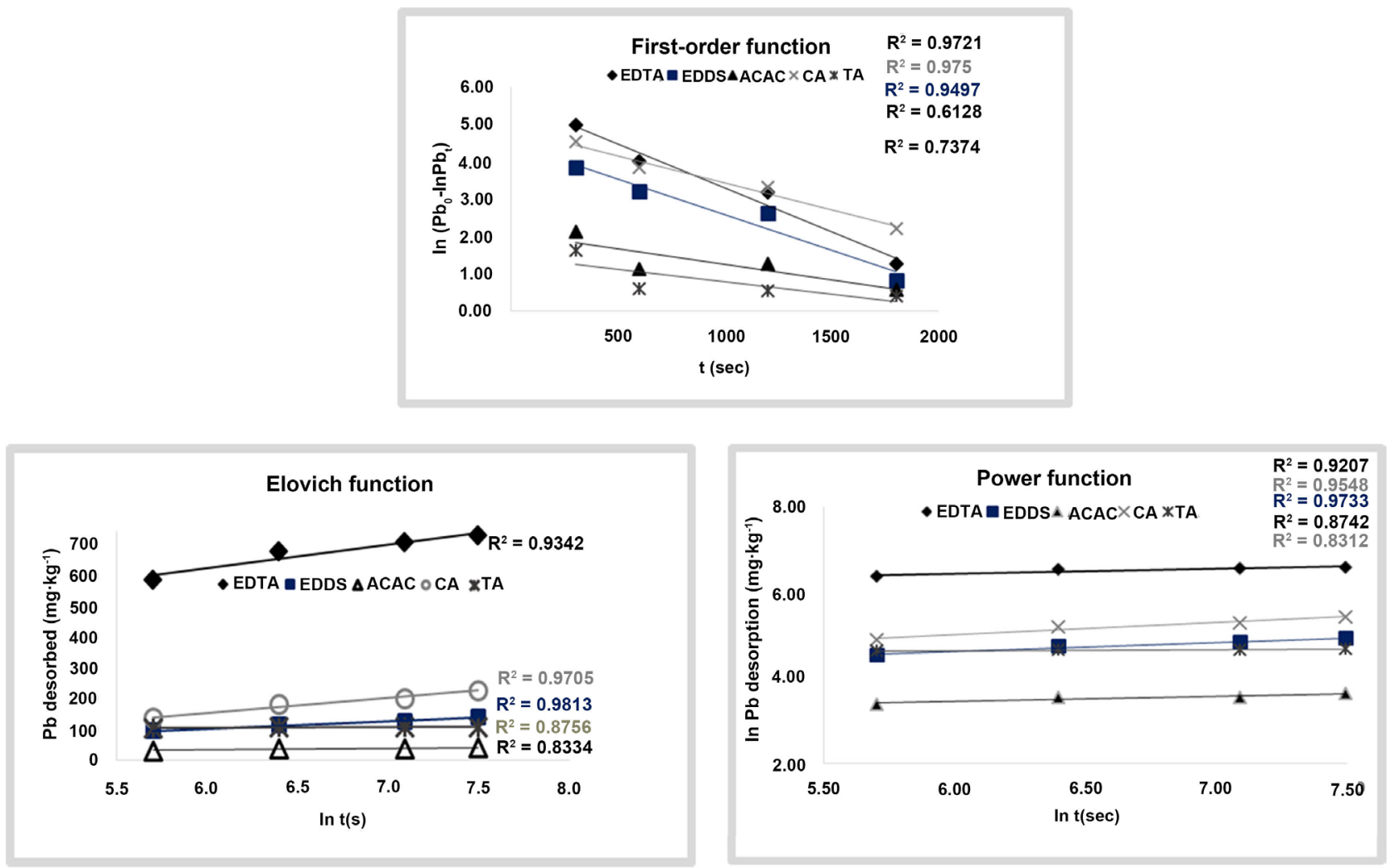

Figure 5. A comparison of $\mathrm{Pb}$ leaching profiles from SS when applying the power function, Elovich and first order equation and using five different extractants.

Although the data fitting for the three equations used in this study yielded a straight line for all the potential metals leached, the first order and simple Elovich equations were not as effective as the power function equation to describe the leaching profiles of the metals from the various substrates. The fitting of the three models to the data represent the extraction of $\mathrm{Pb}$ from SS using the 5 different extractants are illustrated in Figure 5.

\section{Conclusions}

The general trend in the amount of metals leached from the PM, BC and SS, were mostly in the order of $\mathrm{Pb}>\mathrm{Zn}>\mathrm{Ni} \sim \mathrm{Cu}>\mathrm{Cd}$. This could explaine that $\mathrm{Pb}$ and $\mathrm{Zn}$ are relatively easy to leach from contaminated soils or materials, with $\mathrm{Cd}$ being difficult to obtain. In addition, EDTA seems to be the best overall extractant for both SM and MM from SS, outperforming the other extractants by up to 9 times. TA had the lowest performance. The different leaching rates observed for the different metals with the different reagents used, suggests that differential removal from the simulated soil can be achieved, which would ultimately assist in the separation of the various metals in large-scale practical application. This implies that it should be possible to recover particular metals selectively from polluted soils and metallurgical wastes.

In the kinetic extractions evaluated, it is eluded that the power function model 
best described the leaching profiles of the targeted metals, for both single components and the SS. Therefore, it is suggested that the release-determining step is diffusion controlled. This information could be useful for design purposes of the required equipment for large-scale applications of soil remediation/waste recovery plants.

While some success has been demonstrated in this investigation to predict potential heavy metal removal by washing and extraction from soil, the effect of the type of operational configuration (batch, column or heap leaching) has not been determined yet. This aspect will be explored more detailed using a simulated as well as several natural polluted soils in further follow-up work.

\section{Conflicts of Interest}

The authors declare no conflicts of interest regarding the publication of this paper.

\section{References}

[1] FAO and ITPS (2015) Status of the World's Soil Resources (SWSR)-Main Report. Rome, Italy, Ood and Agriculture Organisation of the United Nations and Intergovernmental Technical Panel on Soils.

[2] Lafuente, A.L., Gonzalez, C., Quitana, J.R., Vazquez, A. and Romero, A. (2008) Mobility of Heavy Metals in Poorly Developed Carbonate Soils in the Mediterranean Region. Geoderma, 145, 238-244. https://doi.org/10.1016/j.geoderma.2008.03.012

[3] Oyourou, J.N., Mcrindle, R.I., Combrink, S. and Fourie, C. (2017) Investigation of Zinc and Lead Contamination of Soil of the Abandoned Edendale Mine, Mamelodi (Pretoria, South Africa) Using a Field Portable Spectrometer. Journal of the Southern African Institute of Mining and Metallurgy, 119, 55-61.

[4] Fatoba, P.O., Ogunkunle, C.O., Folarin, O.O. and Oladele, F.A. (2016) Heavy Metal Pollution Ecological Geochemistry of Soil Impacted by Activities of the Oil Industry in the Niger Delta, Nigeria. Environmental Earth Science, 75, 297. https://doi.org/10.1007/s12665-015-5145-5

[5] Wei, B. and Yang, L. (2010) A Review of Heavy Metal Contaminations in Urban Soils Road Dusts and Agricultural Soils from China. Microchemical Journal, 94, 99. https://doi.org/10.1016/j.microc.2009.09.014

[6] Cheng, H. and Hu, Y. (2010) China Needs to Control Mercury Emissions from Municipal Solid Waste (MSW) Incineration. Environmental Science and Technology, 44, 7994-7995. https://doi.org/10.1021/es1030917

[7] Marwa, E.M.M., Meharg, A.A. and Rice, C.M. (2002) Risk Assessment of Potentially Toxic Elements in Agricultural Soils and Maize Tissues from Selected Districts in Tanzania. Science of the Total Environment, 416, 180-186. https://doi.org/10.1016/j.scitotenv.2011.11.089

[8] Kober, B., Wessels, M., Bolhofer, A. and Mangini, A. (1999) Pb Isotopes in Sediments of Lake Constants, Central, Central Europe Constrain the Heavy Metal Pathways and the Pollution History of the Catchment, the Lake and Regional Atmosphere. Geochimica et Cosmochmica Acta, 63, 1293-1303. https://doi.org/10.1016/S0016-7037(99)00064-2

[9] Nunes, J., Ramos-Miras, J., Lopez-Pineiro, A., Loures, L., Gil, C., Coelho, J. and Loures, A. (2014) Concentrations of Available Heavy Metals in Mediterranean Agricultural Soils and Their Relation with Some Soil Selected Properties: A Case 
Study in Typical Mediterranean Soils. Sustainability, 6, 9124. https://doi.org/10.3390/su6129124

[10] Hakanson, L. (1980) An Ecological Risk Index for Aquatic Pollution Control: A Sedimentological Approach. Water Research, 14, 975-1001.

https://doi.org/10.1016/0043-1354(80)90143-8

[11] Doelsch, E., Deroche, B. and Van de Kerchove, V. (2006) Influence of Sewage Sludge Spreading on Heavy Metal Speciation in Tropical Soils (Reunion, Indian Ocean). Chemosphere, 65, 286-293. https://doi.org/10.1016/j.chemosphere.2006.02.046

[12] Herselman, J.E., Steyn, C.E. and Fey, M.V. (2005) Baseline Concentration of Cd, Co, $\mathrm{Cr}, \mathrm{Cu}, \mathrm{Pb}, \mathrm{Ni}$ and $\mathrm{Zn}$ in Surface Soils of South Africa. South African Journal of Science, 101, 509-512.

[13] Barona, A., Aranguiz, I. and Elias, A. (2001) Metal Associations in Soils before and after EDTA Extractive Decontamination: Implications for the Effectiveness and Further Clean-Up Procedures. Environmental Pollution, 113, 79-85. https://doi.org/10.1016/S0269-7491(00)00158-5

[14] Labanowski, J., Monna, F., Bermond, A., Cambier, P., Fernandez, C., Lamy, I. and Oort, F. (2008) Kinetic Extraction to Assess the Mobilization of $\mathrm{Zn}, \mathrm{Pb}, \mathrm{Cu}$ and $\mathrm{Cd}$ in a Metal Contaminated Soil, EDTA vs Citrate. Environmental Pollution, 152, 693-701. https://doi.org/10.1016/j.envpol.2007.06.054

[15] Zhang, W., Huang, H., Tan, F., Wang, H. and Qiu, R. (2010) Influence of EDTA Washing on the Species and Mobility of Heavy Metals Residual in Soils. Journal Hazardous Material, 173, 369-376. https://doi.org/10.1016/j.jhazmat.2009.08.087

[16] Fabbricino, M., Ferraro, A., Del Giudice, G. and d'Antonio, L. (2013) Current Views on EDDS Use for $E_{X}$-Situ Washing of Potentially Toxic Metal Contaminated Soils. Review of Environmental Science and Biotechnology, 12, 391-398. https://doi.org/10.1007/s11157-013-9309-z

[17] Elliott, H.A. and Shastri, N.L. (1999) Extractive Decontamination of Metal-Polluted Soils Using Oxalate. Water, Air and Soil Pollution, 110, 335-346. https://doi.org/10.1023/A:1005067404259

[18] Kesler, S.E. (2010) Geological Stocks and Prospects for Non-Renewable Resources, in Linkages of Sustainability. The MIT Press, Cambridge, 109-129.

[19] Bassi, R., Prasher, S.O. and Simpson, B.K. (2000) Extraction of Metals from Contaminated Sandy Soil Using Citric Acid. Environmental Progress, 19, 275-282. https://doi.org/10.1002/ep.670190415

[20] Reddy, K.R. and Chinthamreddy, S. (2000) Comparison of Different Extractants for Removing Heavy Metals from Contaminated Clayey Soils. Soil and Sediment Contamination, 9, 449-462. https://doi.org/10.1080/10588330091134347

[21] Bradl, H.B. (2004) Adsorption of Heavy Metal Ions on Soils and Soils Constituents. Journal of Colloid and Interface Science, 277, 1-18. https://doi.org/10.1016/j.jcis.2004.04.005

[22] Hong, J. and Pintauro, P.N. (1996) Selective Removal of Heavy Metals from Contaminated Kaolin by Chelators. Water, Air and Soil Pollution, 87, 73-91. https://doi.org/10.1007/BF00696830

[23] de Matos, A.T., Fontes, M.P.F., da Costa, L.M. and Martinez, M.A. (2001) Mobility of Heavy Metals as Related to Soil Chemical and Mineralogical Characteristics of Brazilian Soils. Environmental Pollution, 111, 429-435. https://doi.org/10.1016/S0269-7491(00)00088-9 
[24] Sidle, R.C. and Kardos, L.T. (1997) Adsorption of Cu, Zn and Cd by a Forest Soil. Journal of Environmental Quality, 6, 313-317. https://doi.org/10.2134/jeq1977.00472425000600030017x

[25] Kaschl, A., Romheld, V. and Chen, Y. (2002) The Influence of Soluble Organic Matter from Municipal Solid Waste Compost on Trace Metal Leaching in Calcareous Soils. Science of the Total Environment, 291, 45-57. https://doi.org/10.1016/S0048-9697(01)01091-9

[26] ISO (1999) Soil Quality-Inhibition of Reproduction of Collembola (Folsomia Candida) by Soil. International Standardization Organization, Geneva, Switzerland, ISO 11267.

[27] Pontoni, L., van Hullebusch, E.D., Fabbricino, M., Esposito, G. and Pirozzi, F. (2006) Assessment of Trace Heavy Metals Dynamics during the Interaction of Aqueous Solutions with the Artificial OECD Soil: Evaluation of the Effect of Soil Organic Matter Content and Colloidal Mobilization. Chemosphere, 163, 382-391. https://doi.org/10.1016/j.chemosphere.2016.08.005

[28] Osko, I. and Oleszczuk, P. (2013) Influence of Soil Type and Environmental Conditions on $\mathrm{ZnO}, \mathrm{TiO}_{2}$ and Ni Nanoparticles Phytotoxicity. Chemosphere, 92, 91-99. https://doi.org/10.1016/j.chemosphere.2013.02.048

[29] OECD (1984) Earthworm, Acute Toxicity Tests. OECD Guidelines for Testing of Chemicals, Organisation for Economic Cooperation and Development, Paris, Test No. 207.

[30] ISO (2012) Soil Quality: Effects of Pollutants on Earthworms (Eisenia fetida). Part 2. Determination of Effects on Reproduction.

[31] Goldin, A. (1987) Reassessing the Use of Loss-on-Ignition for Estimating Organic Matter in Non-Calcareous Soils. Communications in Soil Science and Plant Analysis, 18, 1111-1116. https://doi.org/10.1080/00103628709367886

[32] Gawlik, B.M., Lamberty, A., Pauwels, J. and Muntau, H. (2001) Certification of Soil-pH (Suspension of Water and $\mathrm{CaCl}_{2}$ ) and Adsorption Coefficient for Atrazine, 2,4-D and Lindane in Six Different Reference Soils (EUROSOIL) IRMM-442.

[33] Cokca, E. and Birand, A.A. (1993) Determination of Cation Exchange Capacity of Clayey Soils by the Methylene Blue Test. Geotechnical Testing Journal, 16, 518-524. https://doi.org/10.1520/GTJ10291I

[34] Santamarina, J.C., Klein, K.A., Wang, Y.H. and Prencke, E. (2002) Specific Surface Determination and Relevance. Canadian Geotechnical Journal, 39, 233-241. https://doi.org/10.1139/t01-077

[35] Sparks, D.L., Zelanzy, L.W. and Martens, D.C. (1980) Kinetics of Potassium Desorption in Soil Using Miscible Displacement. Soil Science Society of America Journal, 44, 1205-1208. https://doi.org/10.2136/sssaj1980.03615995004400060014x

[36] Jardine, P.M. and Sparks, D.I. (1984) Potassium-Calcium Exchange in a Multireactive Soil System: Kinetics. Soil Science of America Journal, 48, 39-45. https://doi.org/10.2136/sssaj1984.03615995004800010008x

[37] Havlin, J.L. and Westfall, D.G. (1985) Potassium Release Kinetics and Plant Response in Calcareous Soils. Soil Science Society America Journal, 49, 366-370. https://doi.org/10.2136/sssaj1985.03615995004900020019x

[38] Chien, S.H. and Clayton, W.R. (1980) Application of Elovich Equation to the Kinetics of Phosphate Release and Sorption in Soil. Soil Science Society America Journal, 44, 265-268. https://doi.org/10.2136/sssaj1980.03615995004400020013x

[39] Rowell, D.L. (1994) Soil Science: Methods and Applications. Longman, Harlow. 
[40] Kim, C., Lee, Y. and Ong, S.-K. (2003) Factors Affecting EDTA Extraction of Lead from Lead-Contaminated Soils. Chemospere, 51, 845-853. https://doi.org/10.1016/S0045-6535(03)00155-3

[41] Sun, B., Zhao, F.J., Lombi, E. and McGrath, S.P. (2001) Leaching of Heavy Metals from Contaminated Soils Using EDTA. Environmental Pollution, 113, 111-120. https://doi.org/10.1016/S0269-7491(00)00176-7

[42] Peterson, L.W., Moldrup, P., Jacobsen, O.H. and Rolston, D.E. (1996) Relations between Specific Surface Area and Soil Physical and Chemical Properties. Soil Science, 161, 9-21. https://doi.org/10.1097/00010694-199601000-00003

[43] Sokolov, I.A. (1996) Paradigm of Pedology from Dokuchaev to the Present Day. Eurasian Soil Sciences, 29, 222-231.

[44] Buol, S.W, Southard, R.J, Graham, R.J. and McDaniel, P.A. (2011) Soil Genesis and Classification. 6th Edition, Wiley-Blackwell, Oxford, UK, 527 p.

[45] Sun, B., Zhao, F.J., Lombi, E. and McGrath, S.P. (2001) Leaching of Heavy Metals from Contaminated Soils Using EDTA. Environmental Pollution, 113, 111-120.

[46] Moon, D.H., Lee, J.R., Wazne, M. and Park, J.H. (2012) Assessment of Soil Washing for Zn Contaminated Soils Using Various Washing Solutions. Journal of Industrial and Engineering Chemistry, 18, 822-825.

[47] Kovo, G.A., Folasegun, A.D. and Kayode, O.A. (2015) Mechanism on the Sorption of Heavy Metals from Binary Solution by a Low Cost Montmorillonite and Its Desorption Potential. Alexandria Engineering Journal, 54, 757-767. https://doi.org/10.1016/j.aej.2015.03.025

[48] Zhang, W. and Irene, L.M.C. (2006) EDTA-Enhanced Washing for Remediation of $\mathrm{Pb}$ - and/or Zn-Contaminated Soils. Journal of Environmental Engineering, 132, 1282-1288.

[49] Buol, S.W., Hole, F.D., McCracken, R.J. and Southard, R.J. (1997) Soil Genesis Classification. 4th Edition, Iowa State University Press, Ames.

[50] Moon, D.H., Park, J.W., Koutsospyros, A., Cheng, K.H., Chang, Y., Baek, J.R. and Park, J. (2016) Assessment of Soil Washing for Simultaneous Removal of Heavy Metals and Low Level Petroleum Hydrocarbons Using Various Washing Solutions. Environment Earth Science, 75, 884. https://doi.org/10.1007/s12665-016-5690-6

[51] Motaghian, H.R. and Hosseinpur, A.R. (2014) Impact of Sewage Sludge Application on Zinc Desorption Kinetics in Some Calcareous Soils. Environmental Earth Science, 71, 4647-4655. https://doi.org/10.1007/s12665-013-2855-4 